\title{
Stefan Berger y Christoph Conrad, The Past as History. National Identity and Historical Consciousness in Modern Europe. Basingstoke: Palgrave Macmillan, 2015, 570 págs. ${ }^{1}$
}

The Past as History. National Identity and Historical Consciousness es el octavo título de la colección "Writing the Nation Series" producida por el proyecto de investigación europeo "Representations of the Past: the Writing of National Histories in Nineteenth and Twentieth Century". Este proyecto, financiado por la European Science Foundation, estuvo dirigido entre 2003 y 2008 por los autores del libro y Guy Marchal, a quien dedican el libro. El libro se propone dar una visión sintética del papel del pasado en la producción de la identidad nacional en la Europa contemporánea. Dicho de otro modo, busca historiar la relación entre la escritura profesional de la historia y la construcción nacional. El objetivo, dicho de otro modo, consiste en esclarecer cómo los productores profesionales de lo que Michael Oakshott llamó "pasado histórico" participaron -y fueron participados por- en la construcción de la identidad nacional en los Estados-nación de la Europa contemporánea. El objetivo del libro es tan ambicioso como correcto es el resultado.

Si bien la autoría es compartida, es Stefan Berger el aliento que impulsa el libro y la pluma que lo desarrolla. Christoph Conrad es profesor de historia moderna y contemporánea en la Universidad de Ginebra, siendo la historia de la historiografía y la de la opinión pública sus ámbitos de investigación. Stefan Berger es profesor de historia social en la Universidad del Ruhr. Ha sido profesor de historia moderna y de historia europea comparada en Manchester, y su ámbito de investigación se divide en dos objetos claros y distintos, la historia de la historiografía y la historia del nacionalismo. Los dos campos sobre los que este libro se organiza y articula.

Aunque el enfoque del libro se incluye dentro de la historia de la historiografía alemana, el carácter marcadamente ecléctico de las referencias que los autores emplean nos alejan de esa tradición tan solvente como rigurosa para acercarnos al bricolaje propio de la posmodernidad. Ciertamente, ni una tradición tan autónoma y poderosa como la historiografía alemana ha permanecido al margen de la influencia de la posmodernidad y de sus productos intelectuales. Así las cosas, Berger recurre indistintamente a las matrices disciplinares de J. Rüsen, a la sociología del conocimiento de K. Mannheim, al habitus y al homo academicus de P. Bourdieu, al binomio saber/poder de M. Foucault o a las temporalidades propuestas por F. Hartog y R. Koselleck. El bricolaje intelectual, que en origen fue una práctica académica estadounidense, ha venido para sustituir a las escuelas y tradiciones y no parece que tenga intención de marcharse.

The Past as History es una obra de historia de la historiografía que tiene una perspectiva transnacional y comparada. Con ella se pretende historiar la llamada "historia nacional" con la intención de eliminarla o, al menos, hacerla reflexiva, plural, heterogénea y, por todo ello, superable. Es, si aceptamos la división del conocimiento en intereses propuesta por Habermas hace décadas, una historia con un interés práctico o ético, por un lado, y emancipador, por el otro. Es un libro con agenda, pero ésta no es

\footnotetext{
${ }^{1}$ La primera reseña de esta obra apareció en 2016 en la Hungarian Historical Review, 5, 2 (2016): 377383.
} 
explícitamente de la Unión Europea. No, al menos, en apariencia. Lo que sí constituyen estas páginas es un libro arriesgado tanto por el objetivo como por la dimensión de su objeto. Los autores lo saben y por ello renuncian a estudiar lo que en Alemania se llama "cultura histórica" (toda la producción sobre el pasado en todos los campos del saber o de la estética). Bien al contrario, prefieren circunscribirse al discurso histórico producido por los historiadores profesionales, las instituciones en las que se produjo y a las redes profesionales en las que se emitió. Aun así, puede epatar la magnitud del proyecto habida cuenta de la cantidad de lenguas que deben dominarse y la cantidad de referencias que deben consultarse. Las cincuenta páginas de bibliografía y las casi cien páginas de biografías de historiadores de toda Europa dan cuenta del esfuerzo realizado.

Debido al cariz hercúleo de la tarea, los autores se cuidan en salud con múltiples advertencias que, sin embargo, no les procurarán el perdón a ojos de los especialistas en las respectivas historias de la historiografía de cada Estado-nación europeo. Errores como el de situar a Menéndez Pelayo como uno de los principales apologetas del franquismo (p. 263) son, ciertamente, poco excusables. No obstante, no debe olvidarse que estamos ante una síntesis de tamaño casi monstruoso, y que las virtudes de este tipo de libros no están en los detalles sino en la visión del conjunto que nos ofrecen. Y esa visión, lejos de ser vaga o miope, es, a pesar de su carácter sintético, ampliamente sugerente.

Así las cosas, los autores se proponen historiar esa relación entre historiografía profesional y construcción de la nación por medio de la llamada "historia nacional". O lo que es lo mismo, buscan historiar el poder y la longevidad de las "historias nacionales" y su influencia en la formación de las identidades nacionales (p. 373). Los autores asumen de partida que tanto la nación como la historia nacional son productos históricos que nada tienen que ver con una supuesta naturaleza. Adoptan sobre su objeto de estudio, dicho de otro modo, una perspectiva constructivista que conforma la columna vertebral que sujeta y da sentido a todos los capítulos del libro. Todo lector de Eric Hobsbawm, Benedict Anderson o cualquier otro miembro de este enfoque al que pertenece Berger, sabe que las tradiciones y naciones se fabrican e imaginan, y los autores demuestran no solo haberlos leído con atención, sino haberlos metabolizado extraordinariamente bien.

El cuerpo del libro se divide en siete capítulos, siendo el primero la justificación y presentación conceptual y temática del libro, y el último la conclusión. El segundo capítulo se ocupa de la "historia nacional" desde antes del nacimiento del Estadonación, es decir, desde el final de la Edad Media hasta la Ilustración, marcando el Tratado de Westfalia de 1648 un punto de inflexión fundamental, ya que hasta la consolidación del sistema geopolítico westfaliano no puede empezar a hablarse de "historia nacional". El tercer capítulo delinea la invención de las tradiciones nacionales durante la primera mitad del siglo XIX. Arrancando desde el legado universalista de la Ilustración, que hizo posible un concepto universal de nación y que se expresó en términos nacionales (el caso de Voltaire es significativo), el romanticismo no solo no rompe con la Ilustración, como se ha tendido a suponer, sino que bebe de ella. La nación romántica necesitó a la nación ilustrada como la historia romántica necesitó a la historia ilustrada.

El cuarto capítulo, que abarca el periodo 1850-1914, nos presenta la profesionalización de la historiografía y la consolidación "científica" de la "historia 
nacional" de la mano del llamado por Berger "historismo" alemán. Según los autores, el fenómeno se presenta como dos caras de una misma moneda. La extensión transnacional del ideal o ethos científico, que comporta la plena profesionalización de la historiografía, va unida, quizá paradójicamente, al establecimiento de la "historia nacional". Los historiadores, constituidos en una disciplina que ha excluido al escritor amateur, a la filosofía, a la literatura, a las mujeres y a otro tipo de sujetos/objetos, reclaman como práctica e ideal una objetividad que escondía una agenda nacionalizadora tan eficaz como inadvertida. Ciertamente, no debe olvidarse que el historicismo alemán (historismo en el libro) tuvo a Walter Scott, por un lado, y a Hegel, por el otro, a sus dos grandes enemigos. Dicho con nuestras palabras, la constitución de la disciplina reprimió como un "otro" a la filosofía de la historia y a la literatura, que, como afirmó Aristóteles en su Poética, se ocupaba de lo posible y de la estimulación de lo imaginable, no de lo que "en realidad había ocurrido". Pocas cosas más detestables para quien busca la transcripción de la realidad histórica mediante la verdad por correspondencia que quien usa ese pasado como excusa para la reflexión metafísica, la imaginación metafórica, la verosimilitud retórica o la acción política. Para la profesión que se consolida en los Estados-nación con un ethos, el cientificista, y un sujeto/objeto, la historia nacional, todo lo demás estaba, valga la redundancia, de más.

Los historiadores, armados con un método, pues sin éste no hay ciencia; con un ideal, la objetividad; con una institucionalización, la universidad, la academia y las redes de revistas y congresos; y con un criterio de verdad, el de la correspondencia, alcanzaron un prestigio que antes no habían tenido. Gracias a ello, estos profesionales pudieron contribuir con más eficacia que antes a la construcción de la identidad nacional. La lista de políticos historiadores es larga, y Berger no se olvida de ninguno, empezando por Antonio Cánovas del Castillo. Por ello, cuando en el capítulo quinto, el del periodo de entreguerras, la "historia nacional" se hace nacionalista hasta la histeria, la profesión historiográfica, que arrastra debilidades y flaquezas desde finales del siglo XIX debido a sus exclusiones y represiones, no puede resistir la instrumentalización, pues solo se modifica el grado de implicación política, no su naturaleza. La crisis es plena. Y es que una cosa es el ideal de objetividad, que apela a un método que distancia al sujeto del objeto, y otra la neutralidad, posición en la que muchos quisieron presentarse y nadie pudo quedarse.

El sexto y último capítulo temático arroja un balance ambivalente. Su periodo es largo, desde la posguerra de la Segunda Guerra Mundial a la posguerra de la Guerra Fría. Durante este periodo, todos los objetos y sujetos reprimidos por la constitución de la disciplina vuelven de alguna manera para ser completamente subsumidos dentro del marco de la "historia nacional". Para muestra un botón, recuérdese, sin ir más lejos, el título de la célebre obra marxista de E. P. Thompson The Making of the English Working Class. Es en las décadas de 1960 y 1970 cuando la "historia nacional" muestra más costurones y problemas, pero la necesidad de forjar consensos nacionales en la posguerra, tanto en el Oeste como en el Este, por un lado, y el resurgir nacionalista que trajeron los años de 1980 y 1990, por el otro, enterraron la posibilidad de acabar con la "historia nacional". Finalmente, concluyen los autores, la situación de la "historia nacional" sigue siendo contradictoria. En la actualidad este tipo de historia está en una situación de crisis epistémica, debida a la realidad transnacional de nuestro presente, y de gran demanda política, ocasionada por el rechazo a las incertidumbres que esta nueva realidad impone a Europa. El futuro podría muy bien no ser halagüeño para la "historia 
nacional", pero aventurar puede ser prematuro. Durante dos siglos el enfoque nacional ha demostrado su capacidad para absorberlo todo, y eso nos lleva a preguntarle al libro los motivos de esa fortaleza.

Según los autores, la historia nacional es una "master narrative" que designa "a hegemonic framings of accounts which foreground central tendencies in a nation's evolution and define their significance for the present" (p. 11). Debido a su condición de metanarrativa, es decir, de enfoque o forma que organiza y significa el material bajo su influencia o mirada, pudo expandirse al mundo al mismo tiempo que el ethos científico, desplazando a las otras identidades con las que competía. Lo hizo porque es el producto y pieza esencial de la modernidad entendida como expresión de la modernización. Efectivamente, la necesidad de estabilizar y cohesionar lo que la modernización fragmentaba y disolvía en el aire hizo posible que la identidad nacional, ajustada al tipo de mercado reclamado por esa modernización, pudiera reducir a las otras identidades a meras piezas dentro de ella. Los historiadores fueron, por tanto, un engranaje más de la nacionalización que los Estados-nación llevaron a cabo en la contemporaneidad. Dicho de otro modo, la identidad nacional fue un producto de la modernidad, que a su vez fue una fantasía o lógica cultural que hizo aceptable la expansión del modo de producción capitalista tanto en su eclosión como en su consolidación como formación social histórica. Son las necesidades de ésta última las que explican el éxito de la "historia nacional" como parte de la nacionalización de las masas, por un lado, y la constitución de la historia como disciplina, por el otro.

Pero esta perspectiva marxista se encuentra tan ausente del libro de Berger y Conrad como el análisis discursivo de la "historia nacional". Dos ausencias que podrían interpretar más adecuadamente los éxitos y miserias de este tipo de historia en general y de la constitución de la historiografía como disciplina en particular. Efectivamente, la necesidad del capitalismo de fragmentar, especializar y disciplinar el conocimiento ha sido estudiada en relación con la modernidad lo suficiente como para no obviarla. Por otro lado, si de metanarrativas hablamos, es necesario recurrir a Hayden White para enriquecer la exploración de la "historia nacional" entendida como una forma que contiene ya de por sí un contenido moral, político y epistémico implícito. Es precisamente este contenido de la forma oculto el que explica, en última instancia, su victoria sobre las historias que los autores llaman "oposicionales". Queda pendiente, por tanto, corregir estas dos insuficiencias que no empañan, sin embargo, el resultado del libro.

Finalmente, los autores presentan un balance de la "historia nacional" en el contexto de la globalización y el proceso de construcción de la unidad europea. La "historia nacional" sigue existiendo porque siguen existiendo los Estados-nación. Los autores no comparten, por el contrario, el criterio de los liberales nacionalistas que afirman la necesidad de que siga siendo así. Para éstos últimos, la nación es necesaria porque da estabilidad y cohesión al conjunto de la población. Hacen, a la manera del Richard Rorty de Achieving Our Country, de la necesidad virtud. Berger y Conrad apuntan en otra dirección.

Para los autores nada hay de natural ni bondadoso en la comunidad imaginada llamada nación. Y mucho menos en las grandes narrativas que, replicando el síntoma posmoderno capturado por Manuel Cruz como "hacerse cargo del pasado", han llevado a la historia a hacer "mythistory" y a la política a enfangarse en las peores acciones 
imaginables. Para The Past as History, admitiendo que las narrativas no pueden evitarse y que los Estados-nación siguen siendo una realidad, la pluralidad de relatos heterogéneos, flexibles y reflexivos es tan necesaria como necesarios son los ciudadanos que compartan estas mismas características. En una completa adhesión al liberalismo anglosajón frente a Herder y Hegel, los autores celebran la ausencia de identidad europea basada en una gran narrativa. Algo que desean siga siendo así, ya que la unión debe venir del ejercicio del libre raciocinio individual y de la evaluación de los mutuos intereses concretos. The Past as History, dicho en otros términos, tiene un contenido implícito que es expresión y celebración de la situación política actual de la Unión Europea. Tal evidencia, tan sorprendente como grosera, acorta el alcance de lo que es, por otra parte, un gran libro. Sin embargo, de su lectura puede extraerse una pregunta tan fascinante como necesaria: ¿Cómo hacer una historia verdaderamente transnacional? La respuesta, que obligatoriamente debe tener en cuenta que los Estados-nación no han desaparecido, quizá exija una nueva gran narrativa. Sin ella, posiblemente no podrá cartografiarse ni nuestro presente posmoderno ni el futuro en el que nos adentramos.

Miguel Ángel Sanz Loroño

IES Virgen del Carmen

Puerto Real, Cádiz

miguel.biblio@gmail.com

Fecha de recepción: 18 de octubre de 2019.

Fecha de aceptación: 4 de diciembre de 2019.

Publicación: 31 de diciembre de 2019

Para citar este artículo: Miguel Ángel Sanz Loroño, "Stefan Berger y Christoph Conrad, The Past as History. National Identity and Historical Consciousness in Modern Europe. Basingstoke: Palgrave Macmillan, 2015, 570 págs.”, Historiografías, 18 (juliodiciembre, 2019): pp. 122-126. 